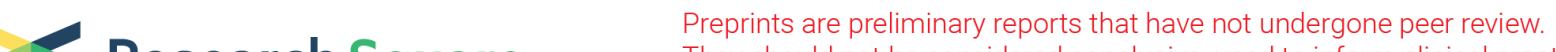 $\begin{array}{ll}\text { Research Square } & \text { They should not be considered conclusive, used to inform clinical practice, } \\ \text { or referenced by the media as validated information. }\end{array}$
}

\section{An Overwhelming Infection After Laparoscopic Transvaginal Natural Orifice Specimen Extraction Procedure for Right Hemi-colonic Radical Resection: A Case Report and Literature Review}

\section{Jian Shi}

Jilin University Second Hospital

Jian-Nan Li

Jilin University Second Hospital

Min Wang

Jilin University Second Hospital

Ling-Yun Yu

Jilin University First Hospital

\section{Xu Han}

Jilin University Second Hospital

\section{Ze-Yun Zhao}

Jilin University Second Hospital

\section{Ting-Ting Yang}

Jilin University Second Hospital

\section{Tong-Jun Liu}

Jilin University Second Hospital

Yong-Ping Yang ( $\nabla$ yongpingyang8301@jlu.edu.cn )

the second hospital of jilin university https://orcid.org/0000-0001-6605-1343

\section{Case report}

Keywords: natural orifice specimen extraction, an overwhelming infection, right hemi-colonic radical resection, case report

Posted Date: March 30th, 2021

DOl: https://doi.org/10.21203/rs.3.rs-350840/v1

License: (9) (1) This work is licensed under a Creative Commons Attribution 4.0 International License. Read Full License 


\section{Abstract}

\section{BACKGROUND}

Laparoscopic transvaginal natural orifice specimen extraction (NOSE) procedure, as one of sub-surgical procedure selections of NOSE, has been well discussed recently. Although most studies argued receiving better post-surgical outcomes than laparoscopic right hemi-colonic radical resection, disadvantages of laparoscopic transvaginal NOSE have seldom been reported. Herein, we reported a case with an overwhelming infection after laparoscopic transvaginal NOSE, even leading a sudden cardiac arrest, and also performed a review of the literature of NOSE, in hopes of expending experience with NOSE for every general surgeon.

\section{CASE PRESENTATION}

A 78-year-old female patient was diagnosis with ascending colon carcinoma (CT3NOMO). After presurgical preparation, a laparoscopic transvaginal NOSE was performed. At the $1^{\text {st }}$ day post-surgery, a septic shock was manifested, with an acute cardiac failure. An intensive care unit therapy was given immediately, including anti-inflammatory therapy, anti-shock therapy, cardiac functional supporting therapy. At the $2^{\text {nd }}$ day post-surgery, there was a sudden cardiac arrest. A cardiac emergency treatment was immediately given to her, following a comprehensive therapy. After a supporting treatment, this patient was discharged from our department at 12 days post-surgically, with a normal manifestation of blood pressure level, breath rate, heart rate, body temperature, white blood cell count, et al. However, a complaint of intermittent precordial pain still existed when discharging from our department. She was transferred to cardiovascular medicine department for a further treatment on cardiac function then. After another 18 days treatment, she left from hospital.

\section{CONCLUSIONS}

Considering many clinical trials on NOSE with positive clinical outcomes, NOSE was recommended to an optional surgical treatment for gastrointestinal carcinoma. However, this case report reminders general surgeons that post-surgical complications to NOSE, some are even fatal, still has possibility to come out. A thorough evaluation pre-operationally and an appropriate therapy post-operationally are crucial and inevitable.

\section{Background}

With an accumulation of clinical trials on laparoscopic colectomy for colonic carcinoma from many different single and/or multiple centers, the advantages of such procedure have been discussed and confirmed by surgeons.[1 2] However, an around $5 \mathrm{~cm}$ incision would be left on abdominal wall for specimen extraction postoperatively. As a solution to deal with such abdominal incision, in recent years, a novel procedure has been carried out, named natural orifice specimen extraction (NOSE) surgery, and been widely used in many countries, due to its benefit of no abdominal wound, fast recovery post- 
operatively, decreased morbidity of incision complications and reduced post-operative pain complaint.[35] Considering majority of clinical studies which argue that NOSE has certain advantages, a point view seems to be prevalent that NOSE could be a safe surgical method, comparing with laparoscopic colectomy.

Although it is a prevailing option that NOSE has many benefits, limitations of such surgical procedure still should not be disregarded. Among common post-operative complications, such as anastomosis leakage, anastomosis bleeding and pelvic abscess, we here reported a case with a unique and rare complication of an overwhelming infection, different from some common inflammation post-operatively, hoping that this case could remind surgeons NOSE is a procedure with strict indications, which is not suitable for every colonic carcinoma case, also can lead to some certain fatal complication, which surgeons have to pay attention to.

\section{Case Presentation}

A written informed consent statement was obtained from the patient, following approval from the Institutional Ethics Committee of the Second Hospital of Jilin University.

\section{Chief complaints}

A 62 year old female patient presented with a complaint of an intermittent right abdominal pain for 2 months.

\section{History of present illness}

This female patient has suffered an intermittent dull pain in the right upper and lower abdominal quadrant for about 2 months. Her complaint was without radiating abdominal pain, without abdominal distension, or without nausea and vomiting. Dark yellow to black stool was discovered for recent 7 days, with reduced frequency of bowel movement, which is about 1 bowel movement for 3-4 days. However, other characteristics of stool was as usual, without pus. She did not receive any hospital service during this period. She only took some laxative for bowel movement. The abdominal pain was improved temperately after medicine taken.

\section{History of past illness}

This patient had a history of hypertension for 10 years, with a highest record of 160/90 mmHg. Her blood tension was controlled at around $130 / 85 \mathrm{mmHg}$ by taking medicine regularly. She denied a history of coronary heart disease or other concomitant diseases. She also denied any history of smoking and drinking. She did not receive any surgery before. Her father died from heart attack, and her mother died from pulmonary infection.

\section{Physical examination}


A physical examination showed us that her overall condition was relatively normal: body mass index (BMI), $23.4374 \mathrm{~kg} / \mathrm{m}^{2}$; blood pressure, $122 / 83 \mathrm{mmHg}$; heart rate, 86 beats per minute; respiratory rate, 16 breaths per minute; oxygen saturation, $100 \%$ on room air; and body temperature, $36.5^{\circ} \mathrm{C}$. Abdominal examination presented a right upper abdominal quadrant tenderness pain, without rebound tenderness or muscular tension. Rectal examination (knee-chest position) had no significant findings.

\section{Laboratory examinations}

Routine laboratory examinations showed that this patient had relatively normal complete blood counts, with white blood cell count (WBC), $5.0 \cdot 10^{9}$ cells/L (normal range is $3.5-9.5 \cdot 10^{9}$ cells/L); percent of neutrophil granulocyte (NG), $67.90 \%$ (normal range is $40.00-75.00 \%$ ); red blood cell count (RBC), $4.16 \cdot 10^{12}$ cells/L (normal range is $4.30-5.80 \cdot 10^{12}$ cells/L); hematocrit (HCT), 33.70\% (normal range is 40.00\%-50.00\%); platelet count (PLT), $278 \cdot 10^{9}$ cells/L (normal range is $125-350 \cdot 10^{9}$ cells/L). Tumor markers examinations also presented a normal result, with carcinoembryonic antigen (CEA), $1.55 \mathrm{ng} / \mathrm{ml}$ (normal range is $0-5 \mathrm{ng} / \mathrm{ml}$ ); and carbohydrate antigen 199 (CA199), $7.23 \mathrm{U} / \mathrm{ml}$ (normal range is 0-37 $\mathrm{U} / \mathrm{ml}$ ). Blood examinations for cardiac function were performed, as b-type natriuretic peptide (BNP), 145 $\mathrm{pg} / \mathrm{ml}$ (normal range is $0-100 \mathrm{pg} / \mathrm{ml}$ ); troponin, $0.001 \mathrm{ng} / \mathrm{ml}$ (normal range is $0-0.03 \mathrm{ng} / \mathrm{ml}$ ).

\section{Imaging examinations}

A colonoscopy revealed the existence of a neoplasm at $70 \mathrm{~cm}$ from anal edge, which had an uneven surface, surrounded by congestive and edematous mucosa. This neoplasm invaded almost $3 / 4$ circumstance of lumen, leading to a bowel obstruction. As a result, the rest of colon could not be scoped. 4 tissue specimens were then obtained from this neoplasm for further pathological biopsy. The biopsy result confirmed a diagnosis of colon carcinoma. A followed computed tomography (CT) scan was performed, with a finding of a tumor-like manifestation at middle site of ascending colon. No swollen lymph nodes was detected surrounding this tumor or retroperitoneum. (Fig. 1)

\section{Final diagnosis}

Based on the coloscopy finding, the result of pathological biopsy, and the CT image, a diagnosis of ascending colonic carcinoma was made. $\left(\mathrm{cT}_{3} \mathrm{~N}_{0} \mathrm{M}_{0}\right)$

\section{Brief surgical procedure}

Once a clinical diagnosis was made, following a routine short-term colon and vaginal antibiotic preparation, a surgical treatment of laparoscopic right hemi-colonic radical resection with transvaginal natural orifice specimen extraction procedure was finally performed on this patient at 12th day after admission. A standard procedure of laparoscopic right hemi-colonic radical resection was performed firstly, of which dissection of mesenteric vessels and lymphadenectomy were guided by the landmark of the superior mesenteric vein (SMV). A specimen of a $20 \mathrm{~cm}$ long ileum from ileocecal valve, ascending colon and partial transcending colon was acquired when such radical resection was finished. Next step was packaging this specimen into a prepared plastic retrieval bag. Then an around $5 \mathrm{~cm}$ incision at 
posterior wall of vagina was performed, in order to fulfill the requirement of specimen extraction from vagina as a natural orifice. The operation time was $125 \mathrm{~min}$, with only $50 \mathrm{ml}$ blood loss occurring.

\section{Histopathological findings}

The middle-low differentiated adenocarcinoma, with component part of mucinous adenocarcinoma. The carcinoma cell infiltrated the serous layer of intestinal wall, and the vein tube was detected carcinoma cell invading. No metastasis evidence was found at ileum, greater omentum or appendix. No metastasis of lymph nodes were found around colon (0/20) or around ileum (0/5). Finally, PTNM staging was T3NOMx. (Fig. 1) An immunohistochemical examination followed. The outcomes were as follows: P53 (30\% positive), Ki67 (80\% positive), BRAFV600E(1 positive), MLH1 (negative), MSH2 (positive), MSH6 (positive), PMS2 (positive), CDX2 (positive), EGFR(positive).(Fig. 2)

\section{Post-operative treatment}

At the 1 st day post-surgery, blood pressure, $84 / 45 \mathrm{mmHg}$; heart rate, 110 beats per minute; respiratory rate, 24 breaths per minute; oxygen saturation, $95 \%$ on oxygen uptake through mask; and body temperature, $38.9^{\circ} \mathrm{C}$. The patient complaint a sleepy, weak, hard breathing and fever condition. Her blood examination showed that WBC was $4.3 \cdot 10^{9} / \mathrm{L}$, percent of NG was $93.20 \%$, percent of lymphocyte was $3.30 \%$, RBC was $3.94 \cdot 10^{12} / \mathrm{L}, \mathrm{Hb}$ was $105 \mathrm{~g} / \mathrm{L}, \mathrm{HCT}$ was $32.80 \%$, PLT was $130 \cdot 10^{9} / \mathrm{L}$, BNP was 4546 $\mathrm{pg} / \mathrm{ml}$ and troponin was $11.272 \mathrm{ng} / \mathrm{ml}$. At that moment, a diagnosis of septic shock and acute cardiac functional failure has been made out. An antibiotic medicine upgrading was immediately carried out. Meantime, this patient was transferred to our intensive care unit (ICU) for further treatment. At the 2nd day post-surgery, she experienced a sudden cardiac arrest with loss of consciousness. An cardiac emergency therapy was executed, including an electric defibrillation. The state of cardiac arrest came over shortly, with a manifestation of blood pressure $102 / 80 \mathrm{mmHg}$, heart rate 102 beats per minute, respiratory rate 18 breaths per minute, oxygen saturation $99 \%$ on oxygen uptake through mask. At that day, the values for assessing infection severity included procalcitonin $11.643 \mathrm{ng} / \mathrm{ml}$ (normal range is 0$0.5 \mathrm{ng} / \mathrm{ml}$ ), interleukin-6 (IL-6) $1312.35 \mathrm{pg} / \mathrm{ml}$ (normal range is $0-6.4 \mathrm{pg} / \mathrm{ml}$ ). An antibiotic therapy continued according blood examinations. Other supportive treatments were also given depending on the patients' conditions and examinations. The values about infection, immune system and cardiac function were all listed in Fig. 3-6.

This patient was almost recovered at 12th day post-surgery, with a normal range of blood pressure $124 / 80 \mathrm{mmHg}$, heart rate 78 beats per minute, respiratory rate 16 breaths per minute, oxygen saturation $100 \%$ on room air. However, an intermittent precordial pain still existed. After a complete physical and laboratory examination by a doctor from the department of cardiovascular internal medicine, this patient was transferred from our department to cardiovascular internal medicine department for further cardiac treatment. After anther 18 days treatment, she discharged from our hospital.

\section{Outcome and follow-up}


After her discharged from our hospital, a six month follow-up was performed by telephone. A blood examination was advised to perform to monitor levels of CEA and CA-199 per 3 months until 2 years post-surgery. Neither a CT scan or a Magnetic Resonance Imaging (MRI) was also suggested to performed per 6 months post-surgery to discovery any evidence of potential recurrence. At the same time, the patient was strongly suggested to undergo 6-8 cycles of CapeOx chemotherapy. Until now, this patient has finished 6 cycles, without experiencing any serious adverse effects, such as neurotoxicity and bone marrow suppression, or any findings of recurrence.

\section{Discussion And Conclusions}

Comparing with conventional laparoscopic abdominal surgeries, one of most obvious advantage of NOSE procedure is absence of an abdominal auxiliary incision, along with minimizing access trauma. Considering incision pain and some incision healing associated issues, NOSE procedure theoretically could reduce use of anesthetic drug for releasing incisional pain and morbidity of incision complications, such as incision hernia and wound dehiscence. [6] For abdominal specimen extraction, transvaginal approach, as one of two mainstream approaches, of which another is transanal approach, has been regarded as a common, uncomplicated and widely used method, due to the reason that vaginal wall is elastic, a larger specimen can be acquired through it.[7-9] Besides this present case colon specimen from right hemicolectomy, gastric specimen from subtotal gastrectomy, liver specimen from liver resection and partial pancreas specimen from distal pancreatectomy are reported to be obtained from vaginal wall incision during NOSE.[10-13] Luyao Zhang et al. have successfully performed laparoscopic pancreaticoduodenectomy through transvaginal NOSE method.[14]

Although advantages of laparoscopic transvaginal NOSE are well recognize, some risks and complications have been observed and drawn attention by surgeons recently. Even though both the amount and length of abdominal incision are reduced maximally, wound infections are still reported occasionally.[8 15] Anastomotic leakage, as one of post-operative complications of conventional laparoscopic surgery, is also observed post laparoscopic transvaginal NOSE.[16 17] Other complications, such as bleeding, internal hernia and abdominal abscess, still exist. Moreover some complications are unique for such NOSE procedure. Abdominal contamination, one of such complications, has already been observed.[4 18]

This present case has experienced an overwhelming infection after laparoscopic transvaginal NOSE procedure for right hemi-colonic radical resection. According to her post-operational clinical examinations files and physical examination findings, abdominal contamination is highly suspected. The reasons for such a rapid infection aggravation, even a septic shock appearance, acute cardiac functional failure and a sudden cardiac arrest are still uncertain, however, immune system dysfunction is supposed to be responsible. As shown in Fig. 5, the count of $\mathrm{T}$ and $\mathrm{B}$ lymphocytes and the count of Natural Killer cells (NK cells) have fallen down to the lowest level at the 3rd day post-operation, which led to cell and humoral immune response largely weaken. There could be an interactive relationship and reciprocal causation between a septic shock and immune dysfunction. Furthermore, the amount of immunocytes 
has not risen up to a normal level when she was transferred to cardiovascular internal medicine department with a normal level of WBC and NG, which might be a reminder that some immune-related malfunction can exist even pre-operationally.

In order to reduce transvaginal NOSE related complications, procedures pre-operation and intra-operation in our department follow these protocols: a) bowel preparations pre-operation are mandatory and indispensable, including intestinal antibiotics application and cathartics for thorough evacuation of lumen; b) preventive disinfected vagina preparation with iodine solution is performed; $c$ ) assessment about immune system function, if necessary, can be done; d) carefully and skillfully cope with suturing incision on posterior vaginal wall; e) properly handle the process of packaging surgical specimen by using retrieval bag. The last protocol should be top crucial among all these protocols depending on our experience. Preventing surgical specimen leakage, especially lumen contents, is not only a consideration on avoiding malignant tumor cells spreading, but also escaping from bacterium invading into peritoneal cavity.

For a novel surgical procedure, it is always top concerned and frequently discussed that short-term and long-term complications, overall survival (OS), disease-free survival (DFS) and intro-surgery safety, including abdominal contamination, distal resection margin results and number of retrieved lymph nodes. Most studies argued that this procedure of NOSE could receive an equal or even a lower incidence of abdominal contamination and intro- and post-surgery infection, compared with laparoscopic surgery.[4 18-20] In terms of short-term complication, abdominal contamination and consequent intra-abdominal infection are crucial issues. To evaluate and prevent infection, Linke GR et al performed bacterium growth routine culture examination through gathering swaps from vaginal posterior fornix and peritoneal cavity at different intervals post-surgically.[21] Some interventions, such as preoperative administration of prophylactic antibiotics, preoperative intestinal lumen preparation, intraoperative peritoneal irrigation, and intraoperative transanal lavage with iodophor water, are recommended by different clinical centers, coming out with promising outcomes.[19 20] However, due to a consideration of possibility of carcinoma cells spreading, our group does not apply intraoperative transanal lavage.

We have performed an analysis on intra-abdominal complications associated with colorectal NOSE surgery for recent years. (Table 1) As shown in Table 1, intra-abdominal infection is one of short-term complications with a low incidence. There has been no reports about an over-whelming infection postsurgery yet. However, infection after laparoscopic transvaginal NOSE procedure is still a short-term complication which should be paid attention to by each surgeon.

Totally speaking, laparoscopic NOSE procedure is one kind of minimal invasive procedures, characterized as a safe, cosmetics surgical method with less short- or long-term complications and fast recovery when compared with conventional laparoscopy. However, some complications, such as anastomotic leakage and wound infection, still happen occasionally. This case report presented an extreme rare case experiencing an overwhelming intra-abdominal infection post-surgically, which even caused a sudden 
cardiac arrest. It should be an alert for each surgeon towards NOSE preparations, surgical procedures and complications.

\section{Abbreviations}

NOSE, natural orifice specimen extraction; BMI, body mass index; WBC, blood cell count; NG, neutrophil granulocyte; RBC, red blood cell count; HCT, hematocrit; PLT, platelet count; CEA, carcinoembryonic antigen; CA199, carbohydrate antigen 199; BNP, b-type natriuretic peptide; CT, computed tomography; SMV, superior mesenteric vein; ICU, intensive care unit; IL-6, interleukin-6; MRI, magnetic resonance imaging.

\section{Declarations}

\section{Acknowledgements}

We appreciate the contributions of all the surgeons, coworkers, and friends involved in this study and thank the editors and reviewers for their help with this manuscript.

\section{Authors' contribution}

YPY, JS and JNL conceived of this study, designed it. JS and JNL draft the manuscript. YPY, JS, JNL, MW and LYY participated in design of this study, acquired the data and analysis of data. XH, ZYZ, TTY and TJL acquire the data. YPY, JS, JNL, MW and LYY participated in manuscript preparation and critical revision. All the authors read and approved the manuscript.

\section{Funding}

No funding was received.

\section{Availability of data and materials}

The data and materials can be made available whenever inquired from the Second Hospital of Jilin University.

\section{Ethics approval and consent to participate}

The collection of patient data was approved by the local ethics committee.

\section{Consent for publication}


The participant has given written consent for her personal and/or clinical details along with identifying images to be published in this study.

\section{Competing interests}

We declare no competing interests.

\section{Author details}

1. the Department of General Surgery, the Second Hospital of Jilin University, Changchun, 130041, China.

2. the Department of Ear Nose and Throat Surgery, the First Hospital of Jilin University, Changchun, 130021, China.

\section{References}

1. Jayne DG, Thorpe HC, Copeland J, Quirke P, Brown JM, Guillou PJ. Five-year follow-up of the Medical Research Council CLASICC trial of laparoscopically assisted versus open surgery for colorectal cancer. Br. J. Surg. 2010;97(11):1638-45 doi: 10.1002/bjs.7160[published Online First: Epub Date]|.

2. Bagshaw PF, Allardyce RA, Frampton CM, et al. Long-Term Outcomes of the Australasian Randomized Clinical Trial Comparing Laparoscopic and Conventional Open Surgical Treatments for Colon Cancer The Australasian Laparoscopic Colon Cancer Study Trial. Annals of Surgery 2012;256(6):915-19 doi: 10.1097/SLA.0b013e3182765ff8[published Online First: Epub Date]|.

3. Saurabh B, Chang S-C, Ke T-W, et al. Natural Orifice Specimen Extraction With Single Stapling Colorectal Anastomosis for Laparoscopic Anterior Resection: Feasibility, Outcomes, and Technical Considerations. Diseases of the Colon \& Rectum 2017;60(1):43-50 doi:

10.1097/dcr.0000000000000739[published Online First: Epub Date]|.

4. Hisada M, Katsumata $\mathrm{K}$, Ishizaki T, et al. Complete laparoscopic resection of the rectum using natural orifice specimen extraction. World Journal of Gastroenterology 2014;20(44):16707-13 doi: 10.3748/wjg.v20.i44.16707[published Online First: Epub Date]|.

5. Park JS, Choi GS, Kim HJ, Park SY, Jun SH. Natural orifice specimen extraction versus conventional laparoscopically assisted right hemicolectomy. Br. J. Surg. 2011;98(5):710-15 doi: 10.1002/bjs.7419[published Online First: Epub Date]|.

6. Liu Z, Efetov S, Guan X, et al. A Multicenter Study Evaluating Natural Orifice Specimen Extraction Surgery for Rectal Cancer. J. Surg. Res. 2019;243:236-41 doi: 10.1016/j.jss.2019.05.034[published Online First: Epub Date]l.

7. de Lacy AM, Rattner DW, Adelsdorfer C, et al. Transanal natural orifice transluminal endoscopic surgery (NOTES) rectal resection: "down-to-up" total mesorectal excision (TME)-short-term outcomes 
in the first 20 cases. Surgical Endoscopy and Other Interventional Techniques 2013;27(9):3165-72 doi: 10.1007/s00464-013-2872-0[published Online First: Epub Date]I.

8. Nishimura A, Kawahara M, Suda K, Makino S, Kawachi Y, Nikkuni K. Totally laparoscopic sigmoid colectomy with transanal specimen extraction. Surgical Endoscopy and Other Interventional Techniques 2011;25(10):3459-63 doi: 10.1007/s00464-011-1716-z[published Online First: Epub Date]|.

9. Aarts JWM, Nieboer TE, Johnson N, et al. Surgical approach to hysterectomy for benign gynaecological disease. Cochrane Database of Systematic Reviews 2015(8) doi: 10.1002/14651858.CD003677.pub5[published Online First: Epub Date]|.

10. Sumer F, Kayaalp C, Ertugrul I, Yagci MA, Karagul S. Total laparoscopic subtotal gastrectomy with transvaginal specimen extraction is feasible in advanced gastric cancer. International Journal of Surgery Case Reports 2015;16:56-58 doi: 10.1016/j.jijscr.2015.08.043[published Online First: Epub Date]|.

11. Truong T, Arnaoutakis D, Awad ZT. Laparoscopic Hybrid NOTES Liver Resection for Metastatic Colorectal Cancer. Surgical Laparoscopy Endoscopy \& Percutaneous Techniques 2012;22(1):E5-E7 doi: 10.1097/SLE.0b013e31823f7596[published Online First: Epub Date]|.

12. Kayaalp C, Yagci MA. Laparoscopic Right Colon Resection With Transvaginal Extraction: A Systematic Review of 90 Cases. Surgical Laparoscopy Endoscopy \& Percutaneous Techniques 2015;25(5):384-91 doi: 10.1097/sle.0000000000000124[published Online First: Epub Date]|.

13. Mofid H, Emmermann A, Alm M, Zornig C. Transvaginal specimen removal after laparoscopic distal pancreatic resection. Langenbecks Arch. Surg. 2013;398(7):1001-05 doi: 10.1007/s00423-013-10923[published Online First: Epub Date]|.

14. Zhang L, Sun D, Zhang Y, Gao F, Guo Y. Natural orifice specimen extraction surgery in laparoscopic pancreaticoduodenectomy: A single-center case series. Int. J. Surg. 2020;82:95-99 doi: 10.1016/j.ijsu.2020.07.043[published Online First: Epub Date]|.

15. Akamatsu H, Omori T, Oyama T, et al. Totally laparoscopic sigmoid colectomy: a simple and safe technique for intracorporeal anastomosis. Surgical Endoscopy and Other Interventional Techniques 2009;23(11):2605-09 doi: 10.1007/s00464-009-0406-6[published Online First: Epub Date]|.

16. Franklin ME, Jr., Liang S, Russek K. Natural orifice specimen extraction in laparoscopic colorectal surgery: transanal and transvaginal approaches. Techniques in Coloproctology 2013;17(1):S63-S67 doi: 10.1007/s10151-012-0938-y[published Online First: Epub Date]|.

17. Tarantino I, Linke GR, Lange J, Siercks I, Warschkow R, Zerz A. Transvaginal rigid-hybrid natural orifice transluminal endoscopic surgery technique for anterior resection treatment of diverticulitis: a feasibility study. Surgical Endoscopy and Other Interventional Techniques 2011;25(9):3034-42 doi: 10.1007/s00464-011-1666-5[published Online First: Epub Date]|.

18. Kantsevoy SV. Infection prevention in NOTES. Gastrointestinal endoscopy clinics of North America 2008;18(2):291-ix doi: 10.1016/j.giec.2008.01.004[published Online First: Epub Date]|. 
19. Ngu J, Wong ASY. Transanal natural orifice specimen extraction in colorectal surgery: bacteriological and oncological concerns. Anz Journal of Surgery 2016;86(4):299-302 doi:

10.1111/ans.13383[published Online First: Epub Date]|.

20. Awad ZT, Griffin R. Laparoscopic right hemicolectomy: a comparison of natural orifice versus transabdominal specimen extraction. Surgical Endoscopy and Other Interventional Techniques 2014;28(10):2871-76 doi: 10.1007/s00464-014-3540-8[published Online First: Epub Date]|.

21. Linke GR, Tarantino I, Bruderer T, et al. Transvaginal access for NOTES: a cohort study of microbiological colonization and contamination. Endoscopy 2012;44(7):684-89 doi: 10.1055/s-00321309390[published Online First: Epub Date]|.

22. Zhao Z, Chen Q, Zheng H, Li J, Zheng S, Zhao E. Retrospective Study of Natural Orifice Specimen Extraction Surgery in Resection of Sigmoid and Rectal Tumors. Journal of Laparoendoscopic \& Advanced Surgical Techniques 2020 doi: 10.1089/lap.2020.0780[published Online First: Epub Date]|.

23. Lendzion RJ, Gilmore AJ. Laparoscopic right hemicolectomy with intracorporeal anastomosis and natural orifice surgery extraction/minimal extraction site surgery in the obese. Anz Journal of Surgery 2020 doi: 10.1111/ans.16416[published Online First: Epub Date]|.

24. Chen CQ, Chen H, Yang MQ, et al. Laparoscopy-Assisted Natural Orifice Specimen Extraction to Treat Tumors of the Sigmoid Colon and Rectum: The Short- and Long-Term Outcomes of a Retrospective Study. Journal of Laparoendoscopic \& Advanced Surgical Techniques 2019;29(6):801-08 doi: 10.1089/lap.2018.0601[published Online First: Epub Date]|.

25. Hu J-H, Li X-W, Wang C-Y, et al. Short-term efficacy of natural orifice specimen extraction surgery for low rectal cancer. World Journal of Clinical Cases 2019;7(2):122-29 doi: 10.12998/wjcc.v7.i2.122[published Online First: Epub Date]|.

26. $\mathrm{Ng} \mathrm{H}-\mathrm{I}$, Sun W-q, Zhao X-m, et al. Outcomes of trans-anal natural orifice specimen extraction combined with laparoscopic anterior resection for sigmoid and rectal carcinoma An observational study. Medicine 2018;97(38) doi: 10.1097/md.0000000000012347[published Online First: Epub Date]|.

27. Wang R, Wei Z, Liu Q, et al. Transanal versus transabdominal specimen extraction in laparoscopic rectal cancer surgery: a retrospective analysis from China. Videosurgery and Other Miniinvasive Techniques 2019;14(2):203-09 doi: 10.5114/wiitm.2018.79529[published Online First: Epub Date]|.

28. Park JS, Kang H, Park SY, Kim HJ, Lee IT, Choi G-S. Long-term outcomes after Natural Orifice Specimen Extraction versus conventional laparoscopy-assisted surgery for rectal cancer: a matched case-control study. Annals of Surgical Treatment and Research 2018;94(1):26-35 doi: 10.4174/astr.2018.94.1.26[published Online First: Epub Date]|.

\section{Table}

Due to technical limitations, table 1 is only available as a download in the Supplemental Files section.

\section{Figures}



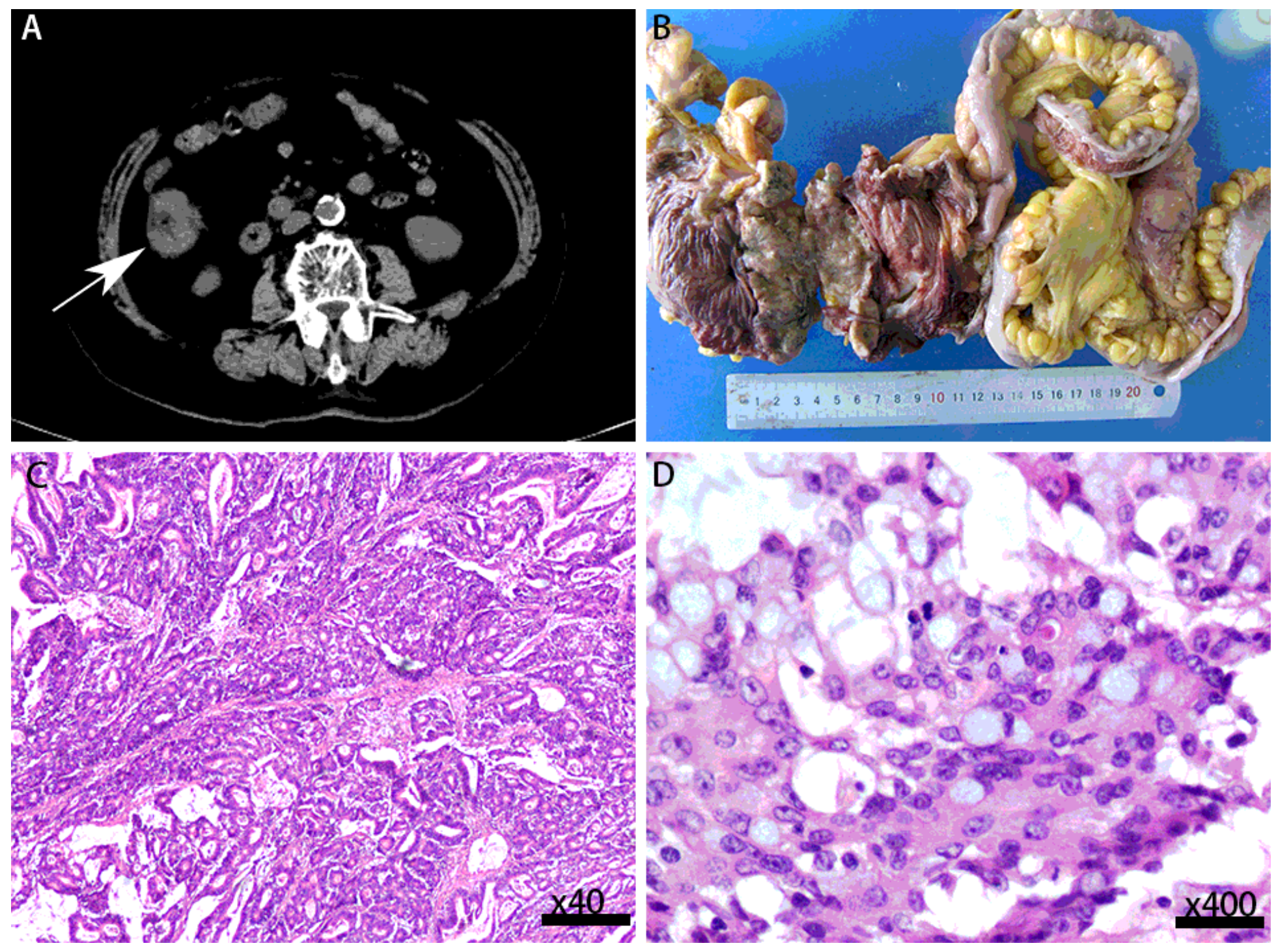

\section{Figure 1}

The manifestation of CT pre-surgery and pathological examination post-surgery. (A) A tumor was found at ascending colon through CT scan pre-surgery. (with white arrow) (B) The specimen of right hemi colon from the patient's body post-surgery. (C) and (D) Middle-low differentiated adenocarcinoma cells were found in specimen slices, with an invasion into the serous layer of intestinal wall. Meanwhile, a component of mucinous adenocarcinoma were also found surrounding. ( $\mathrm{C}$ was $\mathbb{4} \mathrm{40}$ by HematoxylinEosin staining, $\mathrm{D}$ was $\mathbb{8 4 0 0}$ by Hematoxylin-Eosin staining) 

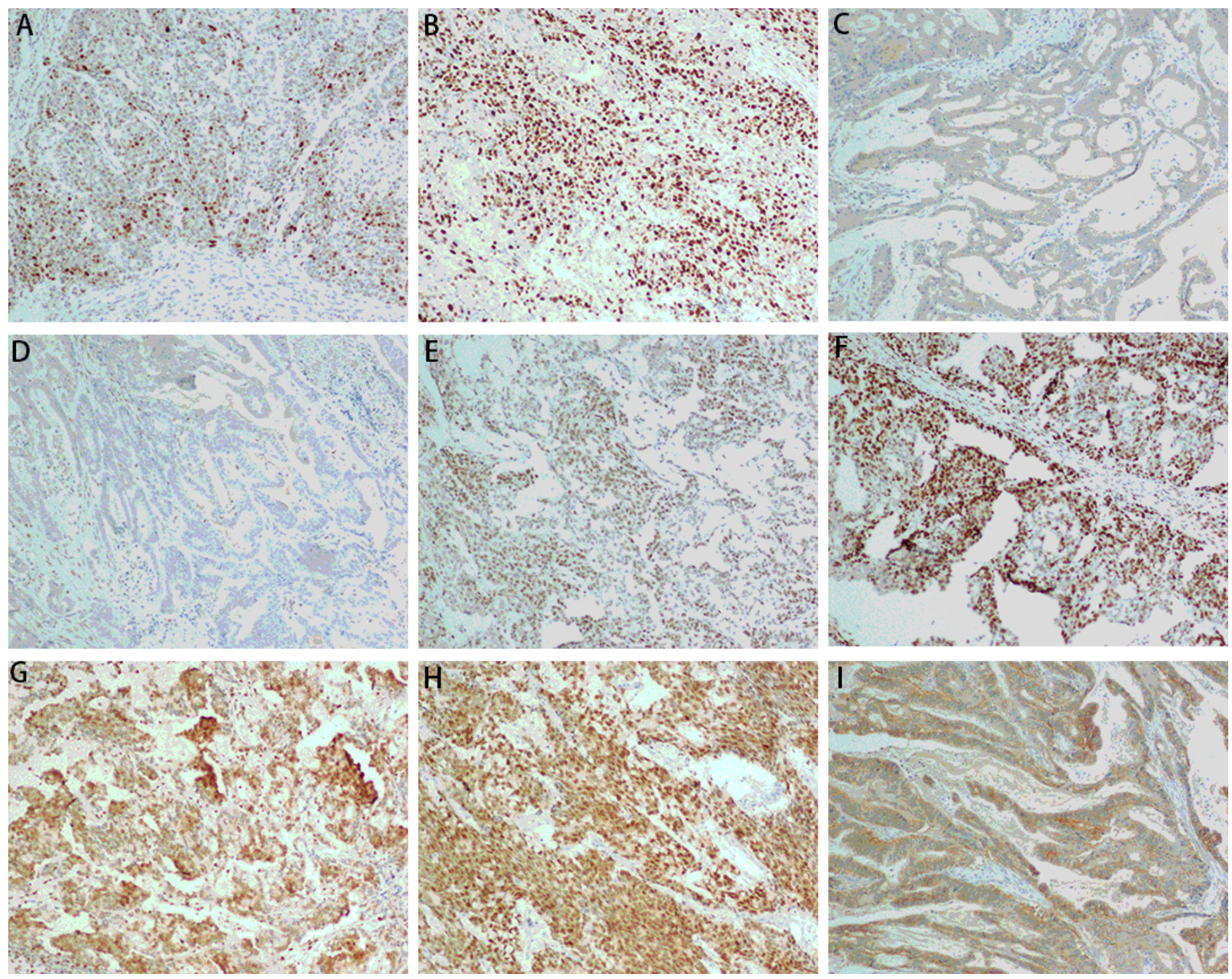

Figure 2

The manifestation of various antibodies of P53, Ki67, BRAFV600E, MLH1, MSH2, MSH6, PMS2, CDX2 and EGFR by an immunohistochemical examination. (A) P53 was $30 \%$ positive. (B) Ki67 was $80 \%$ positive. (C) BRAFV600E was 1 positive. (D) MLH1 was negative. (E) MSH2 was positive. (F) MSH6 was positive. (G) PMS2 was positive. (H) CDX2 was positive. (I) EGFR was positive. 

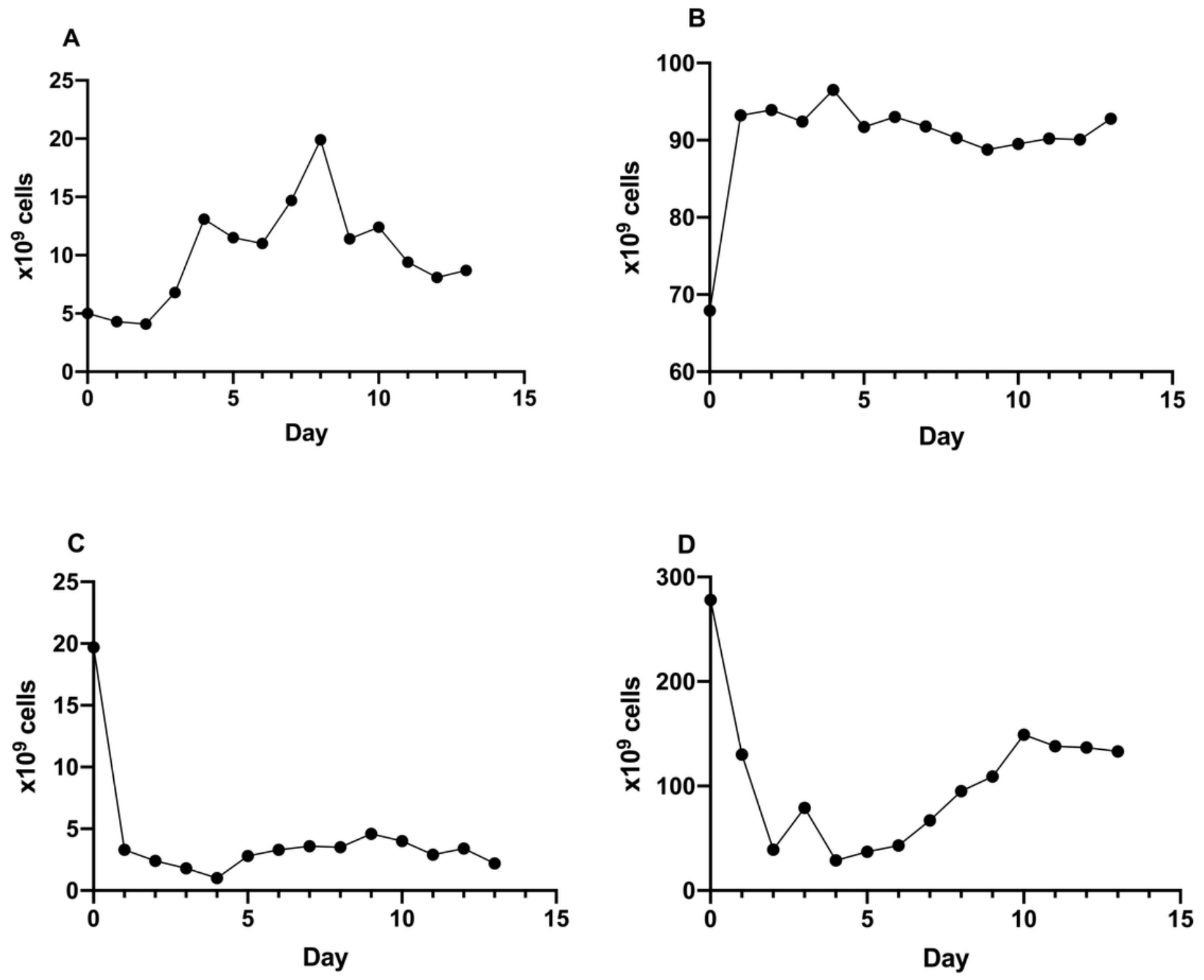

Figure 3

Changes in values associated with infection through blood routine tests on days of pre-surgery (baseline) and 1-13 post-surgery. (A) Changes in White Blood Cell count (WBC). (normal range is 3.5-9.5囚109 cells/L) (B) Changes in percent of Neutrophil Granulocyte (NG). (normal range is $40.00-75.00 \%$ ) (C) Changes in percent of lymphocytes (L). (normal range is $20.00-50.00 \%$ ) (D) Changes in platelet count (PLT). (normal range is 125-350冈109 cells/L) 

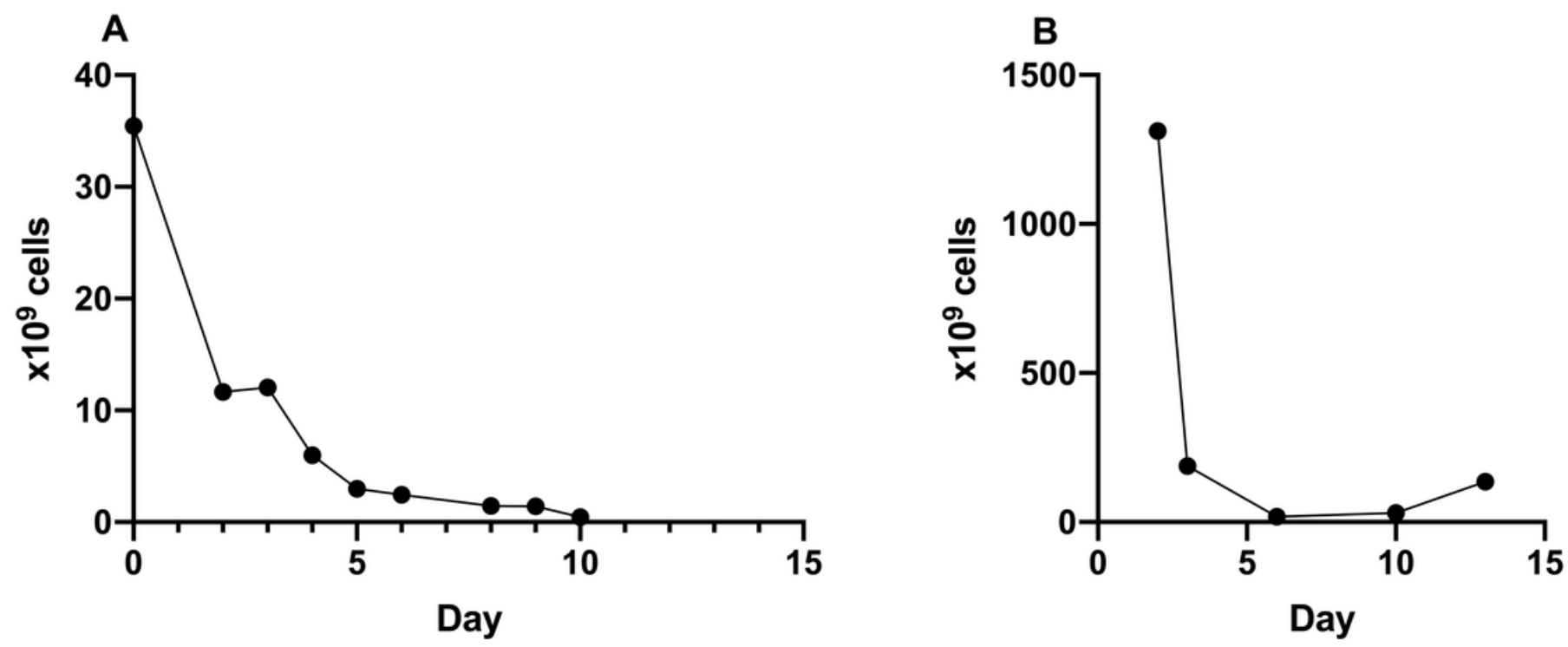

Figure 4

Changes in values associated with infection through procalcitonin and interleukin-6 (IL-6) on days of 1-13 post-surgery. (A) Changes in procalcitonin. (normal range is $0-0.5 \mathrm{ng} / \mathrm{ml}$ ) (B) Changes in IL-6. (normal range is $0-6.4 \mathrm{pg} / \mathrm{ml}$ )

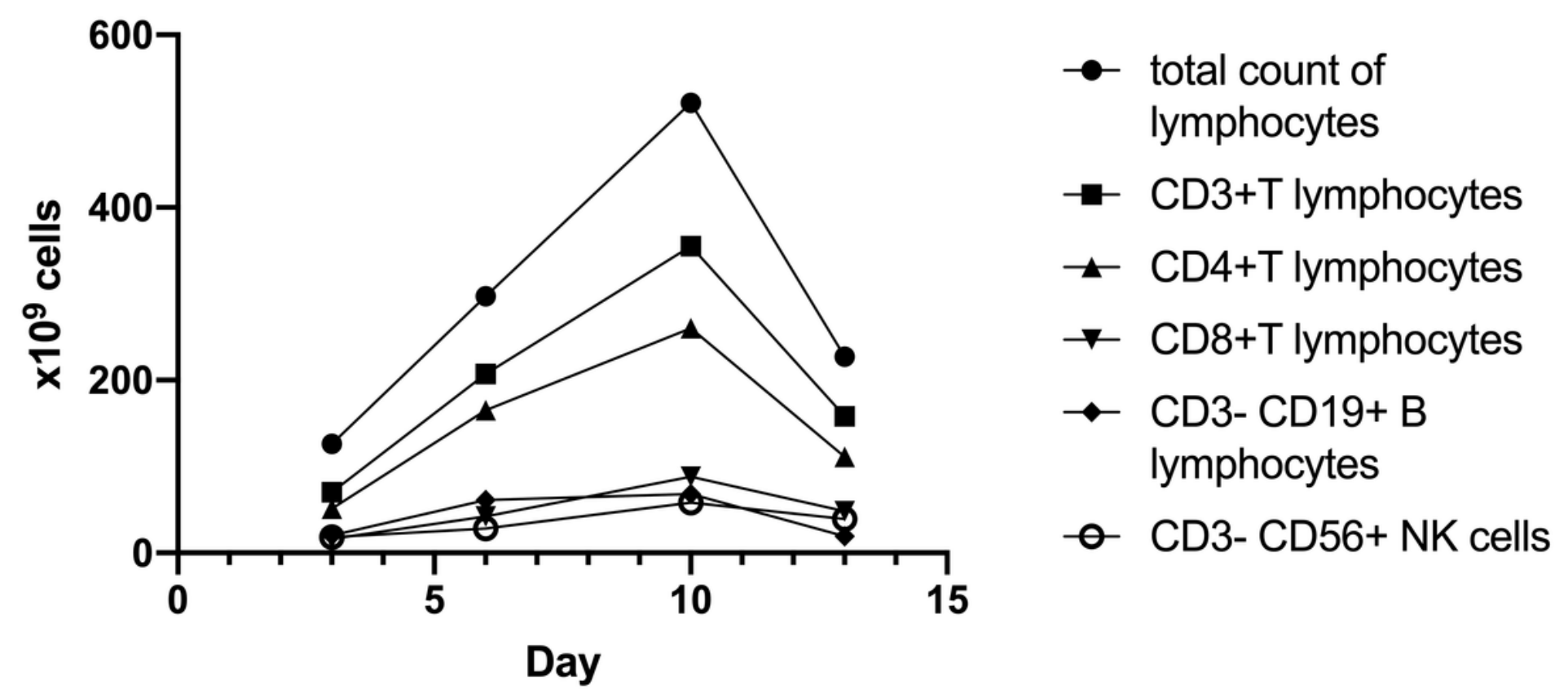

Figure 5

Changes in values associated with immune system on days of $3,6,10$ and 13 post-surgery. Normal range of total count of lymphocytes is $1149.2-2564.7 / \mathrm{uL}$, normal range of CD3+T lymphocytes is 723.51755.5/uL, normal range of CD4+T lymphocytes is 346.4-985.1/uL, normal range of CD8+T lymphocytes 
is 236.3-846.9/uL, normal range of CD3- CD19+ B lymphocytes is 86.6-388.1/uL and normal range of CD3- CD 56+ Natural Killer cells (NK cells) is 130.8-692.5/uL.
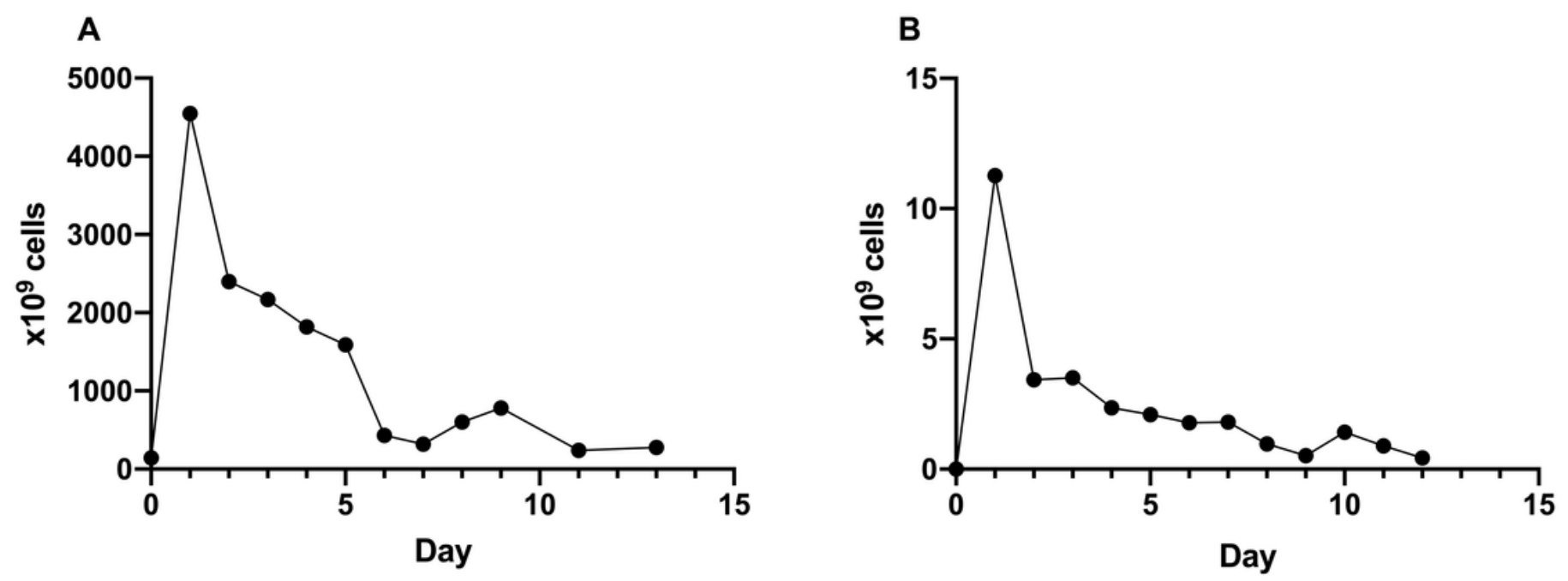

Figure 6

Changes in values associated with cardiac function on days of pre-surgery (baseline) and 1-13 postsurgery. Normal range of b-type natriuretic peptide (BNP) is $0-100 \mathrm{pg} / \mathrm{ml}$, normal range of troponin is 0$0.03 \mathrm{ng} / \mathrm{ml}$.

\section{Supplementary Files}

This is a list of supplementary files associated with this preprint. Click to download.

- Table1.docx 